\title{
INTERNAL RADIO-ECHO REFLECTIONS OF POLAR SNOW COVERS IN RELATION TO ACIDIC LAYERS AND DENSITY FLUCTUATIONS
}

\author{
by
}

FUMIHIKо NisHIO

National Institute of Polar Research, 9-10, Kaga 1-chome, Itabashi-ku, Tokyo, Japan 173

Hirokazu OHMae

Institute of Low Temperature Science,

Hokkaido University, Kita-19, Nishi-8, Kita-ku, Sapporo, Japan 060

\section{ABSTRACT}

To confirm radio-echo layering due to changes in density variations and in specific conductivity in the amount of acid impurities, radio-echo sounding surveys with impulse radar technique were carried out. The continuous and strong internal layers of the snow covers were found to give good correlation with strong peaks of specific conductivity of melted samples from ice cores, rather than the differences in density fluctuations between depositional layers. Measured high conductivity due to acidity variations in ice cores may be correlated with recent volcanic eruptions in the northern hemisphere, and in the Scotia Arc and the South Sandwich Islands.

\section{INTRODUCTION}

Radio-echo sounding records of Antarctica and Greenland have extensively revealed internal layers within large ice sheets, offering a possible means of tracking the internal properties of the ice sheets over large distances. Several physical causes for dielectric changes of the ice producing internal reflections have been offered. Differences in dielectric constant between one layer and another may be caused by differences in density variations, changes in bubble size and shape, impurities (such as a band of volcanic ash) or crystal fabric variations. Each of these causes is glaciologically significant and a better understanding of the internal reflections is needed, but the origin and nature of radio-echo internal reflections have not yet been positively determined.

However, Robin and others (1969), and Paren and Robin (1975) suggested that radio-echo layering in ice sheets is due to two different processes. Density variations between depositional layers may be the main cause of radio-echo layering to depths of some hundreds of meters, and at greater depth where the pressure is too great for density variations to survive, differences in conductivity between layers due to varying amounts of impurities in the snowfall could explain the observed internal layering found in Antarctic records. Recently, Hammer (1977) showed that major impurities affecting the specific conductivity of melted samples from ice cores are due to acidity from major volcanic eruptions, and subsequently confirmed these results by direct measurements of conductivity in ice cores from Camp Century. He also reported that the acid layers in the Crete core are associated with strong echoes to within $\pm 5 \mathrm{~m}$ uncertainty of depth estimates. As a consequence, at present the internal radio-echo reflections are believed to be caused not only by density variations, but also changes in conductivity due to impurities of volcanic eruptions.

To confirm the radio-echo layering due to the changes in density variations and also in conductivity, radio-echo sound surveys using impulse radar technique were carried out by the Japanese Antarctic Research Expedition during glaciological oversnow traverses at G2 station $\left(71^{\circ} 02\right.$ 'S, $\left.39^{\circ} 51^{\prime} \mathrm{E}\right)$ along the Shirase Glacer in Mizuho Plateau, East Antarctica, in 1983. Radio-echo sounding records by impulse radar showed many internal reflections within the polar snow covers at about $25 \mathrm{~m}$ depth below the snow surface.

Density fluctuations and specific conductivity of the melted ice samples were also studied from ice cores drilled to $130 \mathrm{~m}$ depth at $\mathrm{G} 2$ station. In this paper the internal layering of the firn determined by radio-echo sounding is qualitatively compared with fluctuations in snow density and changes of specific conductivity in the amount of acid impurities.

\section{RADAR MEASUREMENTS}

To compare radio-echo reflections with density fluctuations and changes in conductivity of ice cores, the impulse radar technique was used to profile internal layering in the uppermost part of firn down to about $25 \mathrm{~m}$ depth below the snow surface at G2 station. Impulse radar measurements were made by using transmitting-receiving antennae with a center frequency of $300 \mathrm{MHz}$ and 500 $\mathrm{MHz}$, generating a pulse of the order of 3 and 2 nano-seconds respectively. This can be resolved into distinctive layers which appear as single at layers pulse length larger than 2 or $3 \mathrm{~ns}$ (ie $46 \mathrm{~cm}$ or $69 \mathrm{~cm}$ at a density of firn of $400 \mathrm{~kg} / \mathrm{cm}^{3}$ ). The internal reflecting data in the firn were displayed graphically on a strip chart recorder (Figure 1).

The record is an intensity-modulated version of the power return from an internal reflecting layer. Signal amplitudes above a preset theshold level are printed as black, whereas weaker signals remain white. Representative data taken in the vicinity of the borehole at G2 appear in Figure 1.

\section{CONDUCTIVITY MEASUREMENTS}

Specific conductivity profiles have been measured along the ice cores $130 \mathrm{~m}$ long recovered from G2 station. It has been believed that the impurities, particularly of sulphuric acid, greatly influence the specific electrical conductivity of the melted ice, and as we analysed thousands of samples, this simple parameter was chosen as an indicator of internal layering due to variations in loss tangent (Millar 1982) and also volcanic activity (Hammer 1977). Specific conductivity profiles cannot replace comprehensive chemical analysis, but they do reveal important characteristics of volcanic fall-out (Hammer 1977) and may be used as a simple means of showing which of the numerous core increments are promising objects for detailed geochemical analyses.

The cores were sampled in sequence averaging several samples for each annual layer. Individual samples were cut from the cores at $-10^{\circ} \mathrm{C}$ in a cold room after removal of about $5 \mathrm{~mm}$ surface layer that contains essentially all of the relevant contaminants in an undamaged core. Ice samples were melted in clean plastic bags. Conductivity measurements were made by standard procedure and the specific conductivity was determined in ambient air temperature at $25^{\circ} \mathrm{C}$. 


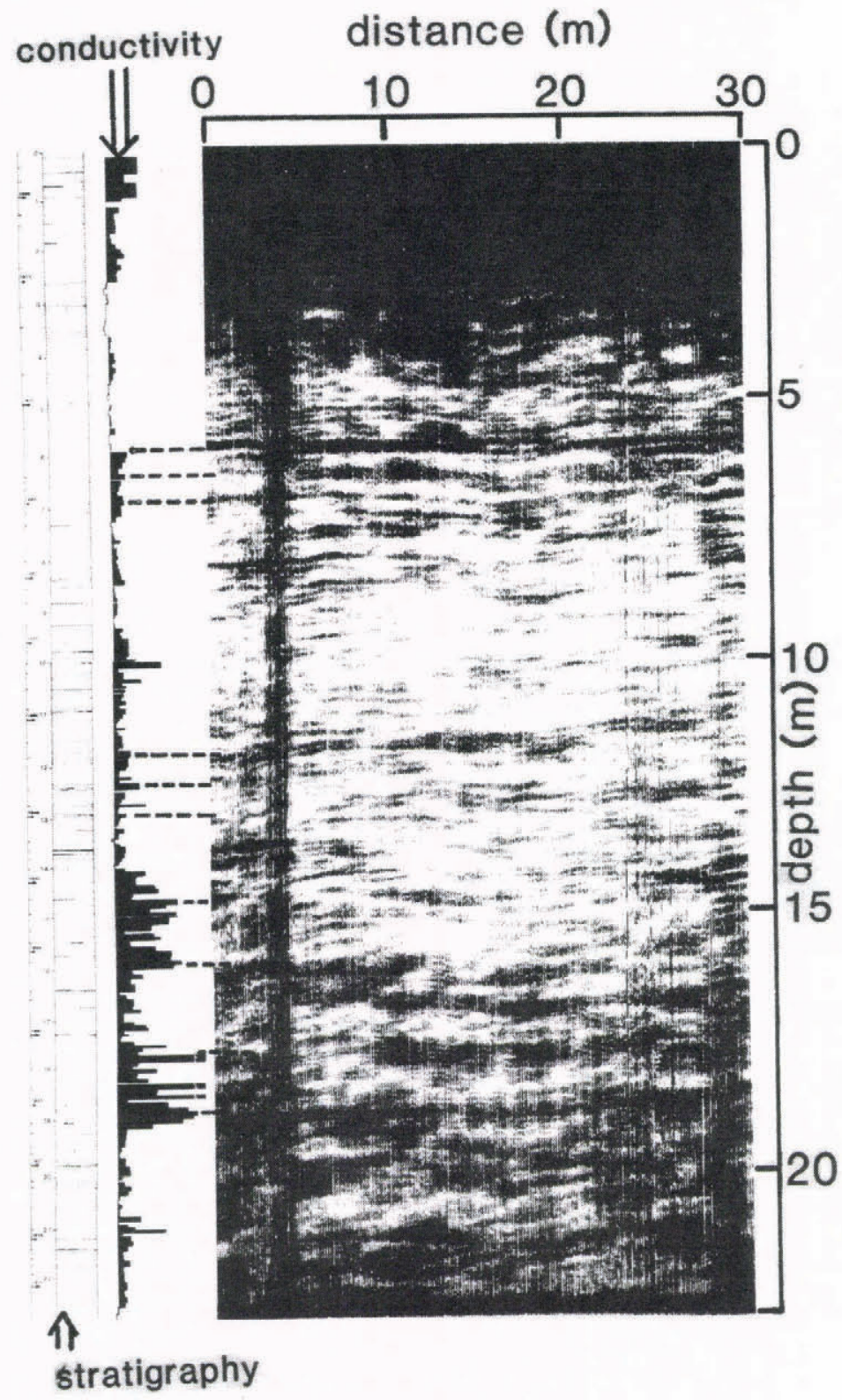

Fig.1. Intensity-modulated record of power return from internal reflecting layers using impulse radar technique with a center frequency of $300 \mathrm{MHz}$. Stratigraphic with a center frequency of $300 \mathrm{MHz}$. Stratigraphic analysis indicating ice layers and specific conductivity of melted samples of ice cores are also shown the mean of $\mathrm{m}$. Values of specific conductivity exceeding the mean of $3 \mu \mathrm{s} / \mathrm{cm}$ are set out in black. Dotted lines connect
specific conductivity with continuous strong signal amplitude.

Specific conductivity with the stratigraphic analysis indicating ice layers along the ice cores down to $23 \mathrm{~m}$ depth is shown in Figure 1; values exceeding the mean of 3 $\mu \mathrm{s} / \mathrm{cm}$ are set out in black.

\section{DENSITY VARIATIONS}

Density measurements amounting to a total of 1033 measurements down to $130 \mathrm{~m}$ depth were conducted: the density profile is shown in Figure 2 (Nishio 1984). Densities were determined with volume measurement and weighing techniques. A rectangular block, approximately $0.05 \mathrm{~m} \mathrm{x}$ $0.05 \times 0.03 \mathrm{~m}$ size, was cut with its wider surfaces perpendicular to the core axis. Its dimensions were measured a few times with a calliper to accuracy of $1 \times 10^{-4} \mathrm{~m}$. The accuracy of weighing was $1 \times 10^{-5} \mathrm{~kg}$, so that the overall accuracy of the density measurements was $\pm 1 \mathrm{~kg} / \mathrm{m}^{3}$. Density fluctuations obtained by the deviations from the moving means of 10 measurements are shown in Figure 3
Density $\left(\mathrm{kg} / \mathrm{m}^{3}\right)$

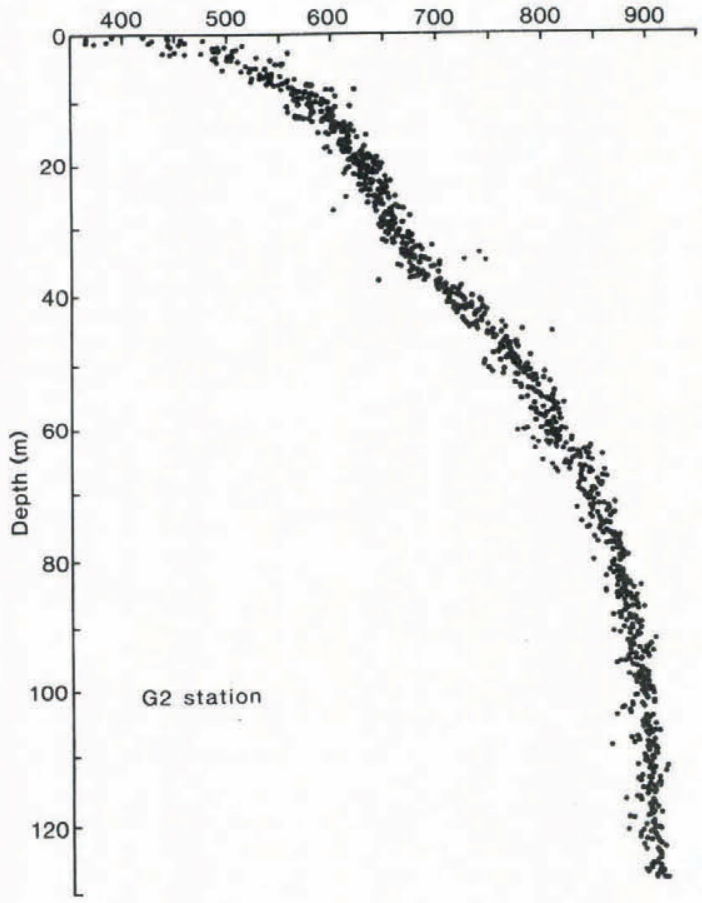

Fig.2. Density profile against depth down to $130 \mathrm{~m}$.

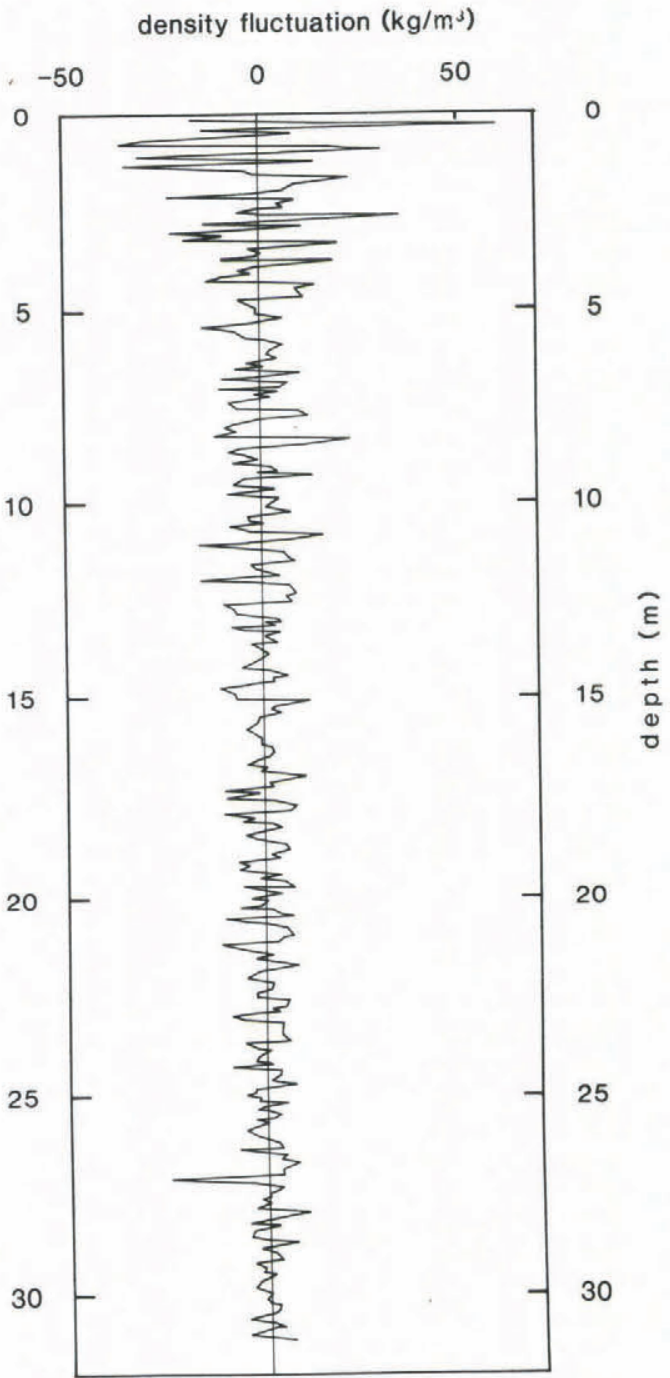

Fig.3. Density fluctuations obtained by deviations from moving means of 10 density measurements. 


\section{RESULTS AND DISCUSSION}

In Figure 1 we have compared the signal strength from the internal reflecting layers printed in black and white with the specific conductivity and stratigraphic analysis indicating the ice layers of ice cores. Dotted lines connect the relatively strong and continuous signal from internal echoes in the firn with specific conductivity and ice layers. Concerning ice layers, a large number exist at depths between $8 \mathrm{~m}$ and $15 \mathrm{~m}$, whereas the graphical display shows the weaker and discontinuous layering on the record. However, the profile of specific conductivity between $6 \mathrm{~m}$ and $14 \mathrm{~m}$ in dpeth reveals small variations, while sudden rises in specific conductivity occur at depths of $14 \mathrm{~m}$ and continue to $19 \mathrm{~m}$ with small variability: the sudden rises in specific conductivity simultaneously indicate the continuous and strong layering. Though the resolution of impulse radar has an order of pulse width generating 2 or $3 \mathrm{~ns}$ (ie $46 \mathrm{~cm}$ or $69 \mathrm{~cm}$ in firn of density $400 \mathrm{~kg} / \mathrm{cm}^{3}$ ) as mentioned in the previous section, the reflecting horizons responsible for layer echoes are probably groups of closely spaced layers forming a reflective zone rather than single layers (Harrison 1973). This has been justified by a comparison of layer echoes detected with a short pulse of 3 ns in Figure 1 with the positions of high conductivity layers. Hence, it may result in good correlation between the high conductivity layers in polar snow cover and the strong and/or continuous layering.

As shown in Figure 3, fluctuations in snow density indicate a large variability in the uppermost part of snow cover above $5 \mathrm{~m}$ depth, and intense signals were received from reflecting layers caused by changes in snow density. Consequently it has been concluded that these layers of high conductivity in the polar snow covers should give rise to the major radar reflecitons rather than layers of snow of changed density as illustrated in Figures 1 and 3.

The measured high conductivity should correspond to variations in loss tangent, believed to occur due to changes in the amount of acid impurities present. Hammer (1977) detected acidic ice layers associated with known volcanic eruptions at sites in Greenland, and layers with a high sulphate content, due to volcanic sulphuric acid, have also been observed in Antarctica at Dome $\mathrm{C}$ and the South Pole (Delmas and Boutron 1980).

Hence, it has been suggested that the measured high conductivity due to acidity variations in ice cores may be correlated with the recent volcanic eruptions in the northern hemisphere, and in the Scotia Arc and the South Sandwich Islands (Nishio and others 1984).

\section{REFERENCES}

Delmas R, Boutron C 1980 Are the past variations of the stratospheric sulfate burden recorded in central Antarctic snow and layers? Journal of Geophysical Research 85(c10): 5645-5649

Hammer C U 1977 Past volcanism revealed by Greenland ice sheet impurities. Nature 270(5637): 482-486

Harrison C H 1973 Radio echo sounding of horizontal layers in ice. Journal of Glaciology 12(66): $383-397$

Millar D H 1982 Acidity levels in ice sheets from radio echo-sounding. Annals of Glaciology 3: 199-203

Nishio F, Katsushima K 1984 Volcanic ash layers in bare ice near the Yamato Mountains in Queen Maud Land and the Allan Hills in Victoria Land in Antarctica. Symposium on snow and ice chemsitry and the atmosphere (unpublished)

Robin G de Q, Evans S, Bailey J T 1969 Interpretation of radio echo sounding in polar ice sheets. Philosophical Transactions of the Royal Society of London, 265(1166):
437-505 